\title{
Xanthomonas Resistance of Phaseolus Interspecific Cross Selections Confirmed by Field Performance
}

\author{
M.E. Scott and T.E. Michaels \\ Department of Crop Science, University of Guelph, Guelph, Ont., \\ Canada N1G 2WI
}

Additional index words. Xanthomonas campestris pv. phaseoli, common bean, plant breeding, disease resistance

\begin{abstract}
Effective genetic resistance to common bacterial blight [Xanthomonas campestris pv. phaseoli (Smith) Dye] is not present in common bean (Phaseolus vulgaris L.) cultivars grown in Ontario. Foliar symptoms and seed yield of white pea bean breeding lines from a $P$. vulgaris/ $P$. acutifolius interspecific cross in the presence and absence of common blight were evaluated. In inoculated plots, seven of the 20 breeding lines did not differ significantly in severity of foliar symptoms from the most resistant controls, XAN 159 and XAN 161. The most susceptible lines tended to have the highest yield when grown under disease-free conditions $(r=0.61$ and 0.49 at two locations). However, the susceptible lines showed an average yield loss of $25 \%$ when disease-free and inoculated plots were compared, while resistant lines had little or no yield loss. The most severely infected lines tended to have the greatest loss in yield $(r=0.72$ and 0.53 at two locations). A resistant breeding line from this study is available as OAC 88-1.
\end{abstract}

Common bacterial blight, caused by Xanthomonas campestris (Xcp) including the brown diffusible pigment-producing strain formerly known as X. campestris pv. phaseoli var. fuscans, produces lesions on leaves, pods, and stems of common bean. This seedborne disease is currently controlled in Ontario by production of disease-free breeder seed in Idaho, where dry climate, stringent cultural practices, and rigorous inspection minimize disease development. Three classes of pedigreed seed-Select, Foundation, and Certified-are subsequently produced in Ontario. These pedigreed seed production fields are inspected for blight once at bloom and again 10 to 14 days later. After harvest, up to 30,000 seeds (depending on the results of field inspections and class of seed) are ex-

Received for publication 20 Aug. 1990. Accepted for publication 28 Oct. 1991. We thank T. Smith and J. Krusky for technical assistance, and the Ontario Ministry of Agriculture and Food and the Ontario Bean Producers' Marketing Board for financial assistance. The cost of publishing this paper was defrayed in part by the payment of page charges. Under postal regulations, this paper therefore must be hereby marked advertisement solely to indicate this fact. amined for blight by the Agriculture Canada Seed-Borne Disease Unit (Sheppard, 1983). Blight tolerance levels for tagged seed are set by the pedigreeing agency, the Canadian Seed Growers' Assn. Effective genetic resistance to common blight is not present in common beans recommended for production in Ontario, and the industry is vulnerable to yield and quality losses if the seed production system fails and seed becomes infected.

The limited resistance to Xcp in the $P$. vulgaris genome has prompted numerous attempts to incorporate resistance from other Phaseolus spp. into P. vulgaris (Coyne and Schuster, 1973, 1974; Honma, 1956; Yoshii et al. 1978). Parker (1985) transferred common blight resistance from $P$. acutifolius A. Gray (tepary bean) into $P$. vulgaris by hybridizing PI 440795 (P. acutifolius) to 'ICA Pijao' (P. vulgaris) and crossing the $\mathrm{F}_{1}$ progeny to 'Ex Rico 23' (P. vulgaris). Lines from this population were selected for white pea been seed type and tested in the field and under growth-room conditions for pod and leaf resistance to common bacterial blight. The purpose of our study was to evaluate the differences in field performance of these lines by comparing their severity of disease symptoms following inoculation with common blight, and the change in seed yield of the lines grown in the absence and presence of common blight.

Two experiments were conducted in 1987, one to evaluate disease resistance and yield of inoculated plants, and another to evaluate yield of uninoculated plants. A combined yield and disease experiment with inoculated and uninoculated seedlots was planted in 1988 at two locations.

Disease experiment (1987). The design was a randomized complete block with three replications and 28 genotypes. Each plot was one row, $6 \mathrm{~m}$ long, with $60 \mathrm{~cm}$ between rows and bordered on either side by one row of 'OAC Seaforth'. Fifty-five seeds were planted in each row. The genotypes included 20 breeding lines derived from the cross 'ICA Pijao'/P.I. 440795//'Ex Rico 23', five genotypes with known resistance to common blight (Great Northern Nebraska \#1 sel.27, XR2351-1-9, XAN 159, XAN 160, XAN 161) (CIAT, 1985; Honma, 1956) and three susceptible control cultivars (ICA Pijao, OAC Seaforth, Ex Rico 23). Two-day-old cultures of Xcp, including standard and brown pigment-producing strains, were mixed in water and adjusted to a concentration of $10^{8} \mathrm{CFU} /$ $\mathrm{ml}$. The seeds were vacuum-infused with inoculum for 10 rein, allowed to dry for $24 \mathrm{~h}$, then planted on 11 June at the Elora Research Station, Elora, Ont. Ratings of disease severity $(0=$ no symptoms, $1=$ necrotic spots only, 2 = a few disease lesions on leaves, $3=$ moderate number of disease lesions on leaves, $4=$ most leaves with large spreading lesions) based on the most severely diseased plant in the plot were made on 17 Aug. Plants were harvested when at least $95 \%$ of pods were tan or brown. Seed yield was adjusted to $18 \%$ moisture. Analyses of variance were conducted on disease severity and seed yield, and a correlation coefficient was calculated for disease severity and seed yield.

Yield experiment (1987). The trials were arranged in a randomized complete block design at two locations with 23 genotypes and four replications. The trials were planted at the Woodstock Research Station, Woodstock, Ont., on 10 June and at the Elora Research Station on 15 June. The entries included the 20 selected breeding lines used in the disease experiment and three susceptible control cultivars, ICA Pijao, OAC Seaforth, and Ex Rico 23. The seeds were harvested the previous year from symptomless plots. Plants were harvested when at least $95 \%$ of the pods were tan or brown. Seed yield was adjusted to $18 \%$ moisture. Analysis of var- 
Table 1. Seed yield $\left(\mathrm{kg} \cdot \mathrm{ha}^{-1}\right)$ and common blight disease ratings of white pea bean breeding lines derived from a Phaseolus vulgaris/P. acutifolius cross and of common bean control entries, Elora and Woodstock, Ont., 1987.

\begin{tabular}{|c|c|c|c|c|}
\hline \multirow[b]{3}{*}{ Entry } & \multicolumn{2}{|c|}{$\begin{array}{l}\text { Inoculated } \\
\text { Elora }\end{array}$} & \multirow{2}{*}{\multicolumn{2}{|c|}{$\frac{\text { Uninoculated }}{\text { Yield }\left(\mathrm{kg} \cdot \mathrm{ha}^{-1}\right)}$}} \\
\hline & \multirow{2}{*}{$\begin{array}{c}\text { Yield } \\
\left(\mathrm{kg} \cdot \mathrm{ha}^{-1}\right)\end{array}$} & \multirow[b]{2}{*}{ Rating ${ }^{2}$} & & \\
\hline & & & Woodstock & Elora \\
\hline BLT $87-1$ & 2431 & 3.2 & 2554 & 3267 \\
\hline BLT $87-2$ & 1790 & 3.7 & 4054 & 3713 \\
\hline BLT $87-3$ & 1998 & 3.5 & 3647 & 2684 \\
\hline BLT $87-4$ & 2666 & 2.0 & 2390 & 3155 \\
\hline BLT $87-5$ & 2638 & 2.2 & 2904 & 3150 \\
\hline BLT $87-6$ & 2707 & 3.3 & 3716 & 3231 \\
\hline BLT $87-7$ & 2174 & 1.8 & 2572 & 2829 \\
\hline BLT $87-8$ & 2573 & 3.2 & 3115 & 3257 \\
\hline BLT $87-9$ & 2072 & 3.0 & 1600 & 2332 \\
\hline BLT $87-10$ & 2250 & 2.8 & 2909 & 3653 \\
\hline BLT 87-11 & 2477 & 3.2 & 3635 & 3894 \\
\hline BLT $87-12$ & 2990 & 3.3 & 4126 & 3616 \\
\hline BLT $87-13$ & 2739 & 1.5 & 2883 & 2996 \\
\hline BLT $87-14$ & 2414 & 2.0 & 2192 & 2274 \\
\hline BLT $87-15$ & 2298 & 2.3 & 2644 & 2531 \\
\hline BLT $87-16$ & 2577 & 3.3 & 2733 & 3234 \\
\hline BLT $87-17$ & 1851 & 2.2 & 2146 & 2791 \\
\hline BLT $87-18$ & 2707 & 3.3 & 4277 & 3178 \\
\hline BLT $87-19$ & 1880 & 1.7 & 2202 & 2729 \\
\hline BLT $87-20$ & 2369 & 3.0 & 2712 & 3097 \\
\hline Ex Rico 23 & 1563 & 3.3 & 3278 & 2866 \\
\hline ICA Pijao & 2649 & 3.2 & 4582 & 3715 \\
\hline OAC Seaforth & 1094 & 4.0 & 2665 & 2220 \\
\hline GN Neb \#1 sel.27 & $\ldots y$ & 2.3 & $\ldots-x^{x}$ & --. \\
\hline XR 235-1-1-9 & -.. & 3.8 & ... & $\ldots$ \\
\hline XAN 159 & $\cdots$ & 1.7 & --- & -.- \\
\hline XAN 160 & ... & 3.2 & --- & ... \\
\hline XAN 161 & $\ldots$ & 1.7 & -- & $\cdots$ \\
\hline $\mathrm{LSD}_{0.05}$ & 422 & 0.6 & 723 & 723 \\
\hline
\end{tabular}

${ }^{2}$ Foliar disease rating scale based on the plant with the most severely diseased leaves in the plot on 17 Aug.; $0=$ no symptoms, $1=$ necrotic spots only, $2=$ a few disease lesions on leaves, $3=$ moderate no. disease lesions on leaves, $4=$ most leaves with large spreading lesions.

y Lines did not mature seed before frost.

*Not included in uninoculated trial.

Table 2. Common blight disease ratings and mean seed yield $\left(\mathrm{kg} \cdot \mathrm{ha}^{-1}\right)$ of white pea bean breeding lines derived from a Phaseolus vulgaris/P. acutifolius cross and common bean control entries over two locations in 1988.

\begin{tabular}{lccc}
\hline \hline & & \multicolumn{2}{c}{ Yleia (kg-na-+) } \\
\cline { 2 - 4 } Entry & $\begin{array}{c}\text { Disease } \\
\text { rating }\end{array}$ & $\begin{array}{c}\text { Disinfected } \\
\text { seed }\end{array}$ & $\begin{array}{c}\text { Innoculated } \\
\text { seed }\end{array}$ \\
\hline BLT 87-2 & $3.7^{\mathbf{x}}$ & $2307^{\mathbf{w}}$ & 1454 \\
BLT 87-4 & 1.7 & 1957 & 1877 \\
BLT 87-5 & 1.9 & 1896 & 1921 \\
BLT 87-6 & 4.0 & 2485 & 1676 \\
BLT 87-7 & 1.6 & 1607 & 1632 \\
BLT 87-11 & 3.6 & 2571 & 1944 \\
BLT 87-12 & 3.2 & 2683 & 2219 \\
BLT 87-13 & 1.2 & 1992 & 2102 \\
BLT 87-14 & 1.4 & 1809 & 1715 \\
BLT 87-15 & 1.4 & 1515 & 1478 \\
BLT 87-19 & 2.2 & 1738 & 1679 \\
ICA Pija0 & 3.2 & 1933 & 1594 \\
Ex Rico 23 & 3.9 & 2554 & 2048 \\
OAC Seaforth & 3.9 & 1866 & 1331 \\
\hline
\end{tabular}

${ }^{2}$ Foliar disease rating scale based on the plant with the most severely diseased leaves in the plot on 15 Aug.; $0=$ no symptoms, 1 = necrotic spots only, $2=a$ few disease lesions on leaves, 3 = moderate number of disease lesions on leaves, $4=$ most leaves with large spreading lesions; $L^{2} D_{0.0 s}=0.4$. y3-min copper acetate solution dip

'Seed vacuum infused for 10 min with Xcp.

${ }^{{ }^{w}} \mathrm{LSD}_{0.05}$ for comparing entry yields within disinfected or inoculated seedlots $=252 ; \mathrm{LSD}_{\mathbf{0 . 0 5}}$ for comparing disinfected and inoculated yields within an entry $=253$.

iance of seed yield was conducted and correlation coefficients for yields in this experiment at each location and disease se- verity of the disease experiment were calculated.

Yield and disease experiment (1988). The trials were arranged in a split-plot design at two locations with four replications. The whole plots represented either inoculation with or freedom from common blight. One-half of each seedlot was inoculated with a mixture of Xcp as described for the 1987 disease trial. The remaining seed was disinfected by dipping for $3 \mathrm{~min}$ in a solution of $1 \%$ copper acetate, $0.01 \%$ Trelon X-10O surfactant (Tween), and $0.05 \mathrm{M}$ acetic acid, followed by drying under forced air (G. Kritzman and L. Edgington, personal communication). The subplots were genotypes consisting of 11 breeding lines advanced from the 1987 field trials and three control cultivars (ICA Pijao, OAC Seaforth, and Ex Rico 23). Each plot was two rows, $6 \mathrm{~m}$ long, with $60 \mathrm{~cm}$ between rows and bordered on either side by one row of 'OAC Seaforth'. Each row was planted with 105 seeds. The trials were planted at the Woodstock Research Station on 17 June and at the Elora Research Station on 20 June. Plots were rated on 15 Aug. for disease severity as described for the 1987 trials. Plots were harvested when at least $95 \%$ of the pods were tan or brown, and seed yield was adjusted to $18 \%$ moisture. Analysis of variance of seed yield was conducted. Correlation coefficients were calculated for the difference in seed yield between uninoculated and inoculated plots and disease severity for each location.

Disease experiment (1987). The seed inoculation method employed in this study appeared to produce uniform infection of plants within plots. Significant differences were found among the 28 entries for disease symptom severity (Table 1). Entry BLT 87 13 , with a rating of 1.5 , had the lowest ranking leaf severity. Seven of the 20 breeding lines were not significantly different in severity from the most resistant controls, XAN 159 and 161.

Fourteen entries produced similar yields as highest yielding control ('ICA Pijao'), and 17 had significantly higher yields than the highest yielding white bean control ('Ex Rico $\left.23^{\prime}\right)$. The yields of these 20 breeding lines were not correlated with the severity of blight infection $(r=0.05, P>0.05)$.

Yield experiment (1987). Three and 13 of the 20 breeding lines at Woodstock and Elora, respectively, produced similar yields as the highest-yielding control, 'ICA Pijao' (Table 1). Three and four were higher yielding than 'Ex Rico 23' at Woodstock and Elora, respectively. There were significant $(\boldsymbol{P}<0.05)$ correlations of 0.61 and 0.49 between yield of the 20 breeding lines in the yield experiment at Woodstock and Elora, respectively, and their severity of infection in the disease experiment at Elora. The higher yielding lines under disease-free conditions generally were those that had the most severe infection under diseased conditions. Three entries, BLT 87-2, BLT 87-10, and BLT 87-11, had large differences in yield at Elora when inoculated and uninoculated seedlots were compared. Eleven of the 20 breeding lines were advanced to the 1988 experiment based on low disease ratings or high yield.

Yield and disease experiment (1988). 
Genotypes differed significantly $(P<0.01)$ in the severity their foliar disease symptoms following inoculation. Six breeding lines had severity values $<2.0$ (Table 2 ). These plants had necrotic spots that were occasionally surrounded by small yellow lesions. All three controls had moderate to large spreading lesions. The main effect of inoculation on seed yield was highly significant $(P<0.01)$ and consistent across both locations. The highly significant $(P<0.01)$ inoculation $\times$ genotype interaction supports the assertion that when resistance was successfully introgressed from $P$. acutifolius it had a tangible impact on seed yield. Entries BLT-4, BLT5, BLT-7, BLT-13, BLT-14, and BLT-15 had 70 scores <2 (resistant) and showed little or no loss yield when inoculated and uninoculated seedlots were compared (Table 2). In contrast, entries BLT 87-2, BLT 87-6, BLT 87-11, BLT 87-12, and all the controls had severity scores $>2$ (susceptible) and showed an average reduction of $25 \%$ in yield between inoculated and uninoculated seedlots. For comparison, Wallen and Jackson (1975), in a study using 'Sanilac' grown in Ontario, estimated yield reduction due to artificially inoculated common blight at $38 \%$ while Yoshii et al. (1976) estimated yield reductions in 'Duva' to be $22 \%$ in naturally inoculated and $45 \%$ in artificially inoculated plots.

There were significant $(P<0.05)$ correlations of 0.72 and 0.53 between severity of blight and yield difference between disinfected and inoculated seedlots at Woodstock and Elora, respectively. Yoshii et al. (1976) also found a highly significant negative correlation between severity of infection and yield. In our study, the most severely infected entries had the greatest loss in yield when uninoculated and inoculated seedlots are compared. The most resistant lines were the least susceptible to changes in yield between inoculated and uninoculated beans. These correlations also suggest that the foliar resistance to common blight introduced from $P$. acutifolius had a substantial impact on seed yield when the plants were grown in the presence of common blight. The difference in yield potential between susceptible and resistant breeding lines can be due to several causes: resistant lines could contain a higher proportion of the unadapted $P$. acutifolius genome than susceptible lines, which, in turn, results in yield depression, or perhaps less likely, the gene or genes associated with resistance could also have a negative impact on yield potential, or could be linked to yield-limiting genes.

Some of the breeding lines with resistance were as high yielding as the best white bean control cultivar (Ex Rico 23) when grown at Elora. The highest-yielding resistant breeding line BLT 87-13 is available to interested researchers from T.E.M. under the name OAC 88-1.

\section{Literature Cited}

CIAT. 1985. Annual report for 1984 on the Bean Program. Centro International de Agricultural
Tropical, Cali, Colombia. p. 46-54.

Coyne, D.P. and M.L. Schuster. 1973. Phaseolus germplasm tolerant to common blight bacterium (Xanthomonas phaseoli). Plant Dis Rptr. 57:111 114.

Coyne, D.P. and M.L. Schuster. 1974. Breeding and genetic studies of tolerance to several bean (Phaseolus vulgaris L.) bacterial pathogens. Euphytica 23:651-656.

Honma, S. 1956. A bean interspecific hybrid. J. Hered. 47:217-220.

Parker, J.P.K. 1985. Interspecific transfer of common bacterial blight resistance from Phaseolus acutifolius A. Gray to $P$. vulgaris L.M.S. Thesis, Univ. of Guelph, Guelph, Ont.

Sheppard, J.W. 1983. Historical perspectives of the production of disease-free seed, control and management of bacterial blight of beans in Canada. Seed Sci. and Technol. 11:885-891.

Yoshii, K., G.E. Galvez, and A. Alvarez. 1976. Estimation of yield losses in beans caused by common blight. Proc. Amer. Phytopathol. Soc. 3:298-299.

Yoshii, K., G.E. Galvez, and G. Alvarez. 1978. Screening bean germplasm for tolerance to common blight caused by Xanthomonas phaseoli and the importance of pathogenic variation to varietal improvement. Plant Dis. Rptr. 62:343347.

Wallen, V.R. and H.R. Jackson. 1975. Model for yield loss determination of bacterial blight of field beans utilizing aerial infrared photography combined with field plot studies. Phytopathology 65:942-948. 